\title{
THERAPEUTIC METHODS USED IN THE TREATMENT OF MALIGNANT LYMPHOMAS OF THE HEAD AND NECK
}

\author{
Mihail TUȘALIU ${ }^{1,2 \bowtie}$, Lavinia G. SAVA ${ }^{1}$, Cristina M. GOANȚĀ ${ }^{1,3}$, Vlad A. BUDU ${ }^{1,2}$ \\ ${ }^{1}$ Institute of Phonoaudiology and Functional ENT Surgery „Prof. Dr. D. Hociotă“, Bucharest, Romania \\ ${ }^{2}$ University of Medicine and Pharmacy „Carol Davila“, Bucharest, Romania \\ ${ }^{3}$ Clinical Emergency Hospital „Sf. Pantelimon“, Bucharest, Romania
}

Received 11 June 2018, Accepted 02 Aug 2018

https://doi.org/10.31688/ABMU.2018.53.3.23

\begin{abstract}
Malignant lymphoma is one of the topical problem of modern medicine. Among head and neck malignancies, lymphoma is the second most common cause. Most of the extranodal lymphomas are represented by non-Hodgkin's lymphomas. Non-Hodgkin's lymphomas localized in the upper aerodigestive tract are classified into three categories, depending on the frequency of these types: oral cavity lymphomas, pharynx and Waldeyer's ring lymphoma, nasal sinuses, throat, pharynx and trachea lymphomas. Main therapeutic approaches used in the therapy of malignant lymphomas are: conventional chemotherapy, radiotherapy, surgery, "salvage" therapy, interferon therapy, monoclonal antibody therapy, bone marrow transplant, peptides treatment. Cytotoxic chemotherapy is the main treatment for medium and high grade malignant lymphomas. However, studies have shown increased toxicity and did not find a significant benefit compared to the use of $\mathrm{CHOP}$ cure (cyclophosphamide, doxorubicin, vincristine and prednisone), both in terms of survival at 3 years and time until therapeutic success. Using third generation of therapeutic protocols allows to achieve complete remission in approximately $50 \%$ of non-Hodgkin's lymphoma cases. Considering the endeavor to
\end{abstract}

\section{Résumé}

Méthodes thérapeutiques utilisées dans le traitement des lymphomes malins de la tête et du cou

Le lymphome malin est l'un des problèmes actuels de la médecine moderne. Parmi les tumeurs malignes de la tête et du cou, le lymphome est la deuxième cause la plus fréquente. La plupart de lymphomes extranodaux sont représentés par des lymphomes non hodgkiniens. Les lymphomes non hodgkiniens localisés dans les voies aérodigestives supérieures sont classés en trois catégories, en fonction de la fréquence de ces types: lymphomes de la cavité buccale, pharynx et lymphome en anneau de Waldeyer, sinus nasal, gorge, pharynx et trachée. Les principales approches thérapeutiques utilisées dans la thérapie des lymphomes malins sont: la chimiothérapie conventionnelle, la radiothérapie, la chirurgie, la thérapie de sauvetage, la thérapie par interféron, la thérapie par anticorps monoclonaux, la greffe de moelle osseuse, le traitement par peptides. La chimiothérapie cytotoxique est le traitement principal des lymphomes malins de grade moyen et élevé. Cependant, des études ont montré une toxicité accrue et n'illustrent pas un bénéfice significatif par rapport à l'utilisation de la cure CHOP (cyclophosphamide, 
diagnose correctly and to adopt an appropriate therapy of a malignant lymphoma suitable in head and neck area, a complex approach, with integration of clinical, morphological and cytogenetic elements, interdisciplinary collaboration between pathologist, hematologist, oncologist, radiotherapist, nutritionist, psychologist, represents the most justified method for a patient with malignant lymphoma.

Keywords: head and neck lymphoma, chemotherapy, radiotherapy.

\section{INTRODUCTION}

Malignant lymphomas represent an important pathology in modern medicine. Cancer is the second cause of death after cardiac diseases, of which leukemia and lymphomas represent the main pathology in patients aged between 20 and 39 years old. Perhaps more than other oncohematological conditions, lymphomas presented in the last years a particular dynamic evolution, including pathogenic aspects, diagnosis, precise nosological classification and therapeutic means. The refinement of molecular biology and molecular genetics techniques, of genetic multiplication, notions difficult to imagine a few decades ago, has allowed an accurate classifications of these disorders ${ }^{1}$.

Among head and neck cancers, lymphomas are the second in frequency, developing in head and neck lymph nodes or as an extralymphatic site. Also, they come second after primary gastrointestinal lymphomas. Head and neck lyphomas include proliferations involving Waldayer's lymphatic ring, nose and paranasal sinuses, larynx, farynx, thyroid gland and salivary glands. In this territory the lymphatic tissue - MALT (mucosa associated lymphoid tissue) is particularly well represented and may be a starting point for various lymphoproliferations. This tissue develops as a response to the increased frequency of chronic inflammation at this level ${ }^{2-4}$.

The onset of malignant lymphoma outside lymph nodes has been more and more common, more than $30 \%$ of malignant lymphomas being diagnosed as originating out of the lymph nodes and presenting pathogenic, clinical and therapeutic particularities ${ }^{5}$. doxorubicine, vincristine et prednisone), tant en termes de survie à 3 ans que de succès thérapeutique. L'utilisation de protocoles thérapeutiques de troisième génération permet d'obtenir une rémission complète dans environ $50 \%$ des cas de lymphome non hodgkinien. Considérant les efforts pour diagnostiquer correctement et adopter une thérapie appropriée d'un lymphome malin approprié dans la région de la tête et du cou, approche complexe, avec intégration d'éléments cliniques, morphologiques et cytogénétiques, collaboration interdisciplinaire entre pathologiste, hématologue, oncologue, radiothérapeute, nutritionniste et psychologue, représente les méthodes les plus justifiées pour aborder un patient atteint d'un lymphome malin.

Mots-clés: lymphome de la tête et du cou, chimiothérapie, radiothérapie.

An important role in the complex evaluation of these patients is atributed to the ENT clinical examination, including inspecting and palpating lateral neck tumors and the entire cervical region as a whole and endoscopic examination of the nose, nasopharynx, oropharynx and larynx, in order to visualize the mucosa of the superior respiratory and digestive tract. Often, clinical evaluation must be completed with paraclinical investigations. The diagnosis of certainty is represented by histopathological examination, which ofers important immunohistochemical and cytogenetic data of the malignant cell, with an important role in the evolution and prognostic of the patients. Only after obtaining a diagnosis of certainty we can determine the optimal treatment for each patient $^{6,7}$.

Most extranodal lymphomas are non-Hodgkin's lymphomas. Non-Hodgkin's lymphomas of the upper respiratory and digestive tract are classified in three main categories, depending on the frequency of these types (Table 1).

Alongside these sites, there have been described lymphomas originating in the salivary glands or in the inner ear structures. All these lymphomas may be accompanied by lateral neck determinations, requiring a differential diagnosis between carcinomas with lateral neck metastasis and malignant lymphopathy with a lymphatic or extralymphatic origin ${ }^{8,9}$.

\section{Therapeutical PROBlems}

The histological, clinical, and evolutionary heterogeneity of malignant lymphomas raises certain therapeutical problems. The therapeutic management of this patology has undergone significant changes 
Table 1. Classification of non-Hodgkin's lymphomas of the upper respiratory and digestive tract.

\begin{tabular}{|c|c|c|}
\hline $\begin{array}{l}\text { Oral, Waldayer's ring and pharynx } \\
\text { lymphomas }\end{array}$ & $\begin{array}{l}\text { Nasal and paranasal sinuses lympho- } \\
\text { mas }\end{array}$ & Pharynx and tracheal lymphomas \\
\hline Small B cell lymphoma & Small B cell lymphoma & Small B cell lymphoma \\
\hline \multirow{2}{*}{$\begin{array}{c}\text { - Marginal B-cell lymphoma, MALT } \\
\text { - Mantle lymphoma } \\
\text { - Follicular lymphoma } \\
\text { - Extramedullary plasmacytoma }\end{array}$} & \multirow{3}{*}{$\begin{array}{c}\text { - Lymphocytic lymphoma } \\
\text { - Follicular lymphoma } \\
\text { - Mantle lymphoma } \\
\text { - Marginal B-cell lymphoma, MALT } \\
\text { - Extramedullary plasmacytoma }\end{array}$} & $\begin{array}{l}\text { - Marginal B-cell lymphoma, MALT } \\
\text { - Extramedullary plasmacytoma }\end{array}$ \\
\hline & & Diffuse large B cell lymphoma \\
\hline Diffuse large B cell lymphoma & & \\
\hline \multirow[t]{3}{*}{$\begin{array}{c}\text { Non Hodgkin's peripheral lymphoma/ } \\
\text { sinonasal area (secondary) }\end{array}$} & Diffuse large B cell lymphoma & \\
\hline & Burkitt lymphoma & \\
\hline & Non Hodgkin's peripheral lymphoma & \\
\hline
\end{tabular}

over time, which allowed the use of modern treatments in the last few years to stop the evolution of the neoplastic process in the hope of possible cure of the disease.

The main therapeutic methods used in malignant lymphoma are conventional chemoteraphy, radiotherapy, surgical treatment, salvage treatment, interferon treatment, monoclonal antibody treatment, medullar transplantation, peptide treatment.

The most common treatment in malignant lymphomas remains conventional chemotherapy ${ }^{2}$. Its use is supported by the fact that two-thirds of the cases of non-Hodgkin's lymphoma are disseminated, being in stages III-IV since the diagnosis ${ }^{1}$. Chemotherapy is commonly used as polychemotherapy and as monotherapy only in selected cases, such as elderly patients with low malignancy lymphomas ${ }^{10}$. Radiotherapy is a therapeutic option used in well-established circumstances and with very precise techniques, depending on the location of the lymph nodes affected by the disease. For a long period of time, it represented the main therapeutic method used in localised forms of disease (stage I) and for low malignancy histologic types. In most cases, it has an auxilliary role, being associated with polychemotherapy. The use of radiotherapy (cobalt therapy) as a primary treatment, has its justification, especially for the cases with bulky tumoral masses.

For non-Hodgkin's lymphomas with low malignancy and in advanced forms, there are several therapeutic approaches. These include „watch and wait“ strategy for patients with no symptoms, which is preferred until the disease progresses and the patient develops bulk adenopathies or systemic symptoms. Moderate treatment, as mono or polychemotherapy, is recommended as the first choice treatment and palliative treatment ${ }^{2}$. Monotherapy using alkylating agents induces a response in $50-80 \%$ of the cases ${ }^{2}$. Cyclophosphamide and chlorambucil are most used, with complete remision obtained after 6-12 months of treatment, its average duration being 24-36 months, with an average survival of 8 years ${ }^{11}$. It is the treatment of choice for patients over 65 years ${ }^{1}$. Polychemotherapy includes a standard CVP cure (cyclophosphamide, vincristine, prednisone) and has a $80-90 \%$ response in complete and partial remissions ${ }^{11}$. The use of more aggressive cures does not have a positive impact on survival ${ }^{1}$. The use of polychemotherapy associated with radiotherapy is useful in patients with localised forms of disease, such as compressive, painful adenopathies or medullar compression. The use of aggressive chemotherapy resulted in an increased percentage of remissions, however it is little used ${ }^{2}$. Most studies demonstrate a permanent tendency towards relapse without greatly improving overall survival ${ }^{12}$. The main therapeutic plans used are COPP (cyclophosphamide, oncovin, procarbazine, prednisone), CHOP -Bleo+If (cyclophosphamide, adriamycin, oncovin, prednisone, bleomycin, interferon). Aggressive radiotherapy consists in total body irradiation and total lymphatic irradiation, which can have up to $100 \%$ response rate with a survival period without relapse at 5 years of $60 \% 1$. Other non-conventional therapeutic methods are represented by alpha interferon, medullar transplantation and monoclonal antibodies with purine analogues treatment ${ }^{1}$. Indolent type B lymphomas benefit from the following treatment options: „watch and wait" strategy, Fludarabine, Anti-CD20 monoclonal antibodies (Rituximab, Gazivaro), CHOP, Rituximab or Rituximab + CHOP (R-CHOP) ${ }^{1}$.

For non-Hodgkin's malignant lymphomas with an intermediate grade of malignancy, poly-chemotherapy is the main therapeutic option, radiotherapy having an auxilliary role, with greater importance in the localized cases without unfavorable prognostic factors and in the forms that evolve with initial or persistent volumetric mass after the application of polychemotherapy ${ }^{2}$. In localised form, the therapeutic regimens include $3-4$ cycles of polychemotherapy 
(CHOP) with targeted radiotherapy, but with unsuccessful survivals recorded in $80 \%$ of cases, or targeted radiotherapy without further treatment, indicated in nonbulky disease stages I or II, with no systemic symptoms ${ }^{1}$.

Extralymphatic infiltration requires special attention because of immediate occult associations (Waldeyer's ring, digestive tract) and the risk of relapse in the central nervous system of sinus lymphomas. In primary extralymphatic lymphomas, localised in Waldayer's ring, in addition to performing a biopsy for histopathological examination, a surgical intervention is preferred in order to remove as much as possible the affected lymphatic tissue (tonsillectomy, complete adenopathy excision) ${ }^{13-15}$.

For disseminated form, the treatment of choice is represented by polychemotherapy, which must led to complete remission. Maximum doses are given and after complete remission, only a few chemotherapy cycles are administered, prolonged therapy increasing toxicity without providing better results ${ }^{16}$. Standard treatment is represented by $\mathrm{CHOP}$. Several other therapeutic associations of second and third generation drugs, such as m-BACOD (Methotrexat + Leucovorin, Bleomycin, Adriablastin, Cyclophosphamide, Oncovin, Dexamethasone), PRO-MACE/ MOPP (Pro-Prednison, Methotrexat, Adriablastin, Cyclophosphamide, Etoposide), MACOP - B (Methotrexat + Leucovirin, Adriablastin, Cyclophosphamide, Oncovin, Prednison, Bleomycin), COPBLAM III (Cyclophosphamide, Oncovin, Prednison, Bleomycin, Adriablastin, Metulan) have been tried in order to obtain improved results ${ }^{2}$. Studies have shown an increased toxicity and do not prove a significant benefit of using incisive treatment compared to CHOP, both in terms of survival at 3 years and duration to success ${ }^{16-18}$.

High-grade malignant lymphomas are still a difficult issue in terms of first-line treatment, and so far there is no consensus ${ }^{19-21}$. In lymphoblastic lymphomas, conventional chemotherapeutic regimens for aggressive lymphomas lead to excellent initial response rates, but most patients recur and eventually die with progressive disease that does not respond to rescue chemotherapy. There is a combination protocol of systemic chemotherapy associated with central nervous system (CNS) prophylaxis, which consists in cyclophosphamide, doxorubicin, vincristine, prednison and methotrexat induction, methrotexat CNS prophylaxis, consolidation using 4 cycles, oral maintenance therapy with methotrexate and 6 mercaptopurine for 12 months. There is a $58 \%$ failure at three years ${ }^{22}$.

The following therapeutic regimens may also be used: RCHOP, R-ICE (Rituximab, Ifosfamid,
Carboplatin, Etoposide), ESHAP (Etoposide, Metilprednisolone, Citarabine, Cisplatin).

Treatment schemes inspired by the treatment of acute lymphoblastic leukemias have also been attempted. A problem in the study remains bone marrow transplantation which, after receiving the first complete remission, may favorably influence the prognosis of patients.

For small cell lymphoma and Burkitt's lymphoma in child, modern protocols only include multiagent chemotherapy and contain Cyclophosphamide in combination with Methotrexate, Doxorubicin, Cytarabine, and/or Vincristine. The adult starts with aggressive chemotherapy (BACT - Carmustina, Cytarabine, Cyclophosphamide, 6-thioguanine or BEAM - Carmustina, Etoposide, Cytarabine, Melphalan) followed by autologous or allogeneic bone marrow transplantation ${ }^{10}$.

The use of third generation therapeutic protocols allows for complete remissions in approximately $50 \%$ of the non-Hodgkin's lymphoma aggressive cas$\mathrm{es}^{2}$. There are $10-15 \%$ of treatment-refractory cases, and $20-30 \%$ of cases recur, relatively early, after complete remission ${ }^{2}$.

\section{Conclusions}

In the context of correct diagnosis and appropriate therapy of a malignant lymphoma with expression in the head and the neck, the complex approach with integration of clinical, morphological and cytogenetic elements, interdisciplinary collaboration of ENT surgeon with pathologist, hematologist, oncologist, radiotherapist, nutritionist, psychologist, represents the most justified method of approaching the patient with malignant lymphoma.

\section{Compliance with Ethics Requirements:}

„The authors declare no conflict of interest regarding this article"

„No funding for this study“

\section{References}

1. Vlădăreanu AM. Actualități în limfoamele maligne nonhodgkiniene, 2002, Bucuresti, Ed. Amaltea: 13-16.

2. Greer P, John P. Wintrobe's Clinical Hematology, 2009; $12^{\text {th }}$ ed., Lippincott Williams and Wilkins, 2071-2130.

3. Essadi I, Ismaili N, Tazi E, et al. Primary lymphoma of the head and neck: two case reports and review of the literature. Cases J 2008;1(1):426.

4. Vlădăreanu AM. Limfoamele în corelație cu virusurile limfotrope. București 2007, Ed. Amaltea, 159; 
5. Oltean G. Limfoamele maligne cu debut extraganglionar. Targu-Mures 2001, Ed. Veritas, 112-133.

6. Vlădăreanu AM. Limfoamele în corelație cu virusurile limfotrope. București 2007, Ed. Amaltea, 17-61.

7. Tușaliu M, Zainea V. Malignant lymphoma with tonsillar onset-comments on a clinical case. Arch Balk Med Union 2013;48(4):435-439.

8. Jaffe ES, Harris NL, Stein H, Vardiman JW. World Health Organization classification of tumors: pathology and genetics of tumours of haematopoietic and lymphoid tissues. Lyon 2001; IARC, Press, 162-167.

9. Feller AC, Diebold J. Histopathology of nodal and extranod al non-Hodgkin's lymphomas. Springer 2004, 6.3: 213-227, 410.

10. Salles G, Shipp M A, Coiffier B. Chemotherapy of non-Hodgkin's aggressive lymphomas. Semin Hematol 1994;31(1):46-49.

11. Case DC. Clinical experience with oral idarubicin in low-grade non-Hodgkin's lymphomas. Res Clin Forums 1996;18(3):35-41.

12. Parker SL, Tong T, Bolden S, et al. Cancer statistics. CA Cancer J Clin 1996;65: 5-27.

13. Tușaliu M, Zainea V. Indications and surgical techniques in malignant sinonasal lymphomas. Arch Balk Med Union 2014;49(1):87-93.

14. Robbins KT, Kong JS, Fuller LM, Goepfert H. A comparative analysis of lymphomas involving Waldeyer's ring and the nasal cavity and paranasal sinuses. J Otolaryngol $1985 ; 14: 7-13$.
15. Tusaliu M, Mogoanta CA, Dobrea CM, Zainea V. Clinical and histological aspects with therapeutic implications in head and neck lymphomas. Rom J Morphol Embryol 2015;56(2):499-504.

16. Clavio M, Rossi E, Truini M, et al. Anaplastic large cell lymphoma: a clinicopathologic study of 53 patients. Leukemia and Lymphoma 1996;22:319-327.

17. Schmitz N, Linch DC, Dreger P, et al. Randomised trial of filgrastim-mobilized peripheral blood progenitor cell transplantation versus autologous bone-marrow transplantation in lymphoma patients. Lancet 1996;347:353-357.

18. Gaynor ER, Dahlbarg S, Fisher RI. Factor affecting reduced survival of the elderly with intermediate and high grade lymphoma: an analysis of SWOG-516 (INT 0067) - The National High Priority Lymphoma Study - a randomised comparison of CHOP vs mBACOD vs ProMACE-CytaBOM vs MACOP (abstract 1250). Proc Am Soc Clin Oncol 1994:13:370

19. Paraschiv B, Dediu G, Iancu A, Bratu O, Diaconu C. Superior vena cava syndrome - review. Arch Balk Med Union 2017;52(1):39-43.

20. Diaconu C, Paraschiv B. Radiation induced lung disease: a risk to assume. Arch Balk Med Union 2016;51(2): 298-300.

21. Diaconu CC, Paraschiv B, Frecea A, Toma CL, Bogdan M. A young woman with dyspnea: the unusual association of two different diseases. Arch Balk Med Union 2013; 48(2):229-231.

22. Fisher RI, Gaynor ER, Dahlberg S, et al. Comparison at a standard regimen $(\mathrm{CHOP})$ with three intensive chemotherapy regimens for advanced non-Hodgkin's lymphoma. N Engl J Med 1993;328-1002. 